\title{
Treatment of refractory intestinal acute GvHD using multipotent mesenchymal stromal cells (MMSC)
}

\author{
Darya S. Dubnyak, Larisa A. Kuzmina, Mikhail Y. Drokov, Natalia A. Petinati, Nina J. Drize, Vera V. Vasilyeva, Olga M. Ko- \\ roleva, Ekaterina D. Mikhaltsova, Natalia N. Popova, Elena N. Parovichnikova, Valerii G. Savchenko
}

National Research Center For Hematology, Moscow, Russian Federation

Contact: Dr. Darya Dubnyak

E-mail: darya-dubnyak@yandex.ru

\section{Introduction}

Allogeneic hematopoietic stem cell transplantation (allo-HSCT) in patients with hematological malignancies is frequently accompanied by severe complications. E.g., acute graft versus host disease (aGvHD) is common in recipients of peripheral stem cells or bone marrow, thus being among the main reasons of increased mortality or suboptimal life quality during post-transplant period. The aim of this study was to assess efficacy of multipotent mesenchymal stromal cells (MMSCs) in patients with refractory clinical forms of aGvHD with affection of gastrointestinal tract (GIT).

\section{Patients and methods}

One-hundred-eighty allo-HSCT have been performed at the National Research Center of Hematology (Moscow) between November 2012 and June 2016. Fifteen cases of refractory aGvHD with GIT involvement have been diagnosed. We studied efficacy of MMSC application as a second-line therapy for such GvHD cases: fifteen patients with refractory aGvHD and GIT involvement participated in the study, including eight males and 7 females, at a median age of 40 (21 to 57 years old). Eight patients were admitted with acute myeloid leukemia (AML), and five patients were treated for acute lymphoid leukemia (ALL). Patients with myelodysplastic syndrome $(n=1)$, and chronic myeloid leukemia $(n=1)$ were also included. Two patients underwent myeloablative conditioning regimen versus 13 cases with reduced intensity conditioning regimen. In 10 cases, peripheral blood stem cells have been used. Twelve patients were subjected to unrelated allo-HSCT (matched, 8, mismatched, 4). Three patients underwent allo-HSCT from related donors (matched, 2; mismatched, 1). We used different immunossupressive therapy as a preventive treatment of GvHD: MMF+CSA+MTX $(n=9), C S A+M M F(n=3), M M F+$ post-translant cyclophosphamide on $+3,4$ day $(n=1)$, post-translant cyclophospha- mide on $+3,+4(n=1)$. In case of unrelated donor, ATG was added to the therapy. GvHD was established on an average of day +54 after HSCT. Six patients were diagnosed with aGVHD of gastrointestinal tract, 3 patients, with aGVHD affecting GIT and skin; two patients, with aGVHD of GIT and liver; four patients had aGVHD with GIT, liver and skin involvement. The most patients suffered from severe form of GvHD (grade 2 was confirmed in 1 case, grade 3, in 8 cases, grade 4 , in 6patients).

\section{Results}

We administered prednisolone at the dose of $2 \mathrm{mg} / \mathrm{kg}$, as upfront therapy,. In 2 cases only partial response was achieved. We did not achieve any response to prednisolone in 12 patients. One patient with refractory form GvHD died due to malignancy progression. Fourteen patients who failed to respond for the first-line therapy were subjected to the second-line treatment. The therapy was started at an average of 14 days ( 8 to 58 ) since the diagnosis of aGvHD. In thirteen patients, MMSC were applied at $1 . .3$ doses ( 1 dose $=1 \times 106$ / kg MSCs) weekly. In one patient, ATG was administrated as a second-line therapy, however, without any response. In 2 of 13 patients, a "full" response to MMSC therapy was achieved. Moreover, we have got a partial response in 5 patients and did not observe any response in 6 patients. Four patients died from further GvHD progression accompanied by infectious complications. One patient further developed a chronic form of GvHD. In 7 cases, we tried a third-line therapy of aGvHD, with average onset time of 29 (17 to 97 days) since the aGvHD diagnosis. Different therapies were use in these cases. E.g., MMSC were applied in one patient with a partial response to therapy; ATG was injected in 2 patients without clinical effect. Usage of methotrexate in three patients brought a partial effect only in one case case and was entirely ineffective in two cases. Infliximab injection in 1 patient was also without effect. Three patients from the "third-line" group further died from progressing GvHD. A 
next-line therapy was tried in four patients who failed to respond to previous treatment. Tacrolimus was administered in 1 case, ATG, in 1 patient, rituximab, in 2 cases. These patients died from further GvHD progression and concomitant infectious complications. The three-year overall survival was 17.7\%. Conclusions: At present, there is no precise concept for treatment of refractory aGvHD. Our study has shown that the second-line therapy with MMSC may be effective in $57 \%$ of the patients with severe aGvHD complicated by GIT affection . Moreover a "full" response was achieved in 14\% of the cases. We didn't observe any differences of efficacy in terms of MMSC source, i.e., if the same or another donor should be recruited. Third-line and subsequent therapies were proven to be entirely ineffective.

\section{Keywords}

Hematopoietic stem cell transplantation; refractory GVHD; intestinal, prednisolone; mesenchymal stem cells.

\section{Лечение рефрактерной острой реакции «трансплантат против хозяина» (оРТПХ) с поражением кишечника с использованием мультипотентных мезенхимных стволовых клеток (ММСК)}

Дарья С. Дубняк, Лариса А. Кузьмина, Михаил Ю. Дроков, Наталья А. Петинати, Нина И. Дризе, Вера А. Васильева, Ольга М. Королева, Екатерина Д. Михальцова, Наталья Н. Попова, Елена Н. Паровичникова, Валерий Г. Савченко

Федеральное государственное бюджетное учреждение Гематологический научный центр Москва, Россия

\section{Введение}

Проведение трансплантации аллогенных гемопоэтических стволовых крови (алло-ТГСК) при онкогематологических заболеваниях связано с развитием ряда тяжелых осложнений. Одним из них является острая реакция трансплантат против хозяина (оРТПХ). Хотя был достигнут большой успех в профилактике и лечении этого осложнения, до настоящего момента острая реакция трансплантат против хозяина является основной причиной нарушения качества жизни и летальности после алло-ТГСК. Целью работы было изучение эффективности использования мультипотентных мезенхимальных стромальных клеток (ММСК) и других лекарственных средств у больных с рефрактерными формами оРТПХ с поражением кишечника.

\section{Пациенты и методы}

В ФГБУ ГНЦ МЗ РФ в период с ноября 2012г по июнь 2016г выполнено 180 алло-ТГСК. У 15 пациентов была констатирована рефрактерная форма оРТПХ с поражением кишечника. В исследовании проведен анализ эффективности терапии второй и более линий, в том числе с использованием ММСК. В исследование было включено 15 пациентов с рефрактерными формами оРТПХ с поражением кишечника. Медиана возраста пациентов составила 40 лет (21 - 57 лет) из них мужчин - 8, женщин - 7. Диагноз острого миелобластного лейкоза был установлен у 8 пациентов, острого лимфобластного лейкоза - 5 больных, у 1 пациента - миелодиспластический синдром, хронический миелолейкоз - у 1 больного. Двум пациентам было проведено предтрансплантационное кондиционирование в миелоаблативном режиме, 13 - в режиме пониженной интенсивности. В большинстве случаях, в качестве источника трансплантата использовали гемопоэтические стволовые клетки крови - у 10 пациентов. У 12 пациентов алло-ТГСК выполнена от неродственных доноров (полностью совместимых - 8, частично совместимых - 4), у 3 больных алло-ТГСК выполнена от родственных доноров (полностью совместимых - 2, частично совместимый донор - 1). Профилактика РТПХ проводилась по следующим схемам: микофенолата мофетил+циклоспорин+метотрексат $(\mathrm{n}=9)$, микофенолата мофетил + циклоспорин $(\mathrm{n}=3)$, микофенолата мофетил+ циклоспорин $(\mathrm{n}=1)$, микофенолата мофетил + циклофосфамид (+3,4 дни) (n=1), циклофосфамид (+3,4 дни) (n=1), в случае ТКМ от неродственных доноров к проводимой терапии был добавлен АТГ. Медиана развития оРТПХ составила 54 дня после трансплантации. У 6 пациентов констатирована РТПХ только с поражением кишечника, у 9 человек развилось сочетанное поражение: РТПХ кишечника+ кожи у 3 больных, РТПХ кишечника + печени у двоих больных, РТПХ кишечника + кожи+ печени у 4 пациентов. У большинства исследуемых пациентов отмечались тяжелые формы РТПХ (II степени - 1 пациент, III степени - у 8, IV степени - у 6 больных).

\section{Результаты}

В качестве первой линии терапии всем пациентам проводили лечение преднизолоном в дозе 2 мг/кг, частичный ответ был достигнут у трех пациентов, без ответа - две- 
надцать больных. Один пациент, у которого не было достигнуто ответа от лечения РТПХ, погиб от прогрессии основного заболевания. Вторую линию терапии рефрактерной РТПХ с поражением кишечника проводили четырнадцати больным. Медиана начала терапии составила 14 дней от момента диагностики оРТПХ (8-58 дней). Проводили лечение мультипотентными мезенхимальными стромальными клетками - 13 пациентов, 1-3 введения ММСК донора в дозе $1 \times 10^{6} /$ кг с интервалами в 1 неделю. У одного пациента в качестве второй линии использовали АТГ. Среди 13 пациентов, которым введены ММСК полный ответ был получен у двух больных, частичный ответ - 5, ответа не достигнуто - 6 пациентов. После АТГ не было достигнуто какого-либо ответа. 4 пациента погибли от дальнейшего прогрессирования РТПХ, тяжелых инфекционных осложнений, у 1-го больного развилась хроническая форма РТПХ. Терапия третьей линии выполнена семи больным. Медиана назначения лечения составила 29 дней от диагностики оРТПХ (17-97 дней). Пациентам проведена терапия по различным схемам: с помощью ММСК - 1 больной, при этом был достигнут частичный ответ, АТГ использовали у двоих больных положительного ответа не достигнуто, метотрексат вводился троим больным - частичный ответ констатирован только у одного пациента, без ответа - 2 больных, инфликсимаб вводился 1 пациенту также без ответа. Три пациента из 7 в этой группе, в дальнейшем погибли, в том числе и те, у кого был достигнут частичный ответ. Четвертая линии терапии рефрактерной РТПХ с поражением кишечника, проводилась четырем пациентам, не ответившим не на одну из линий терапии. Такролимус применялся у 1 пациент, АТГ - 1 пациент, Ритуксимаб 2 пациентов, ни у одного пациента не достигнуто положительного ответа от лечения, все пациенты погибли от прогрессии РТПХ, инфекционных осложнений. Таким образом, вероятная общая выживаемость пациентов с рефрактерной формой оРТПХ с поражением кишечника составила 17,7\%., в течение трех лет.

\section{Заключение}

В настоящее время не существует единой концепции в лечении рефрактерной РТПХ. В нашем исследовании при использовании в качестве второй линии терапии оРТПХ с использованием ММСК у 57 \% больных отмечен положительный эффект, при этом полный ответ - в $14 \%$ случаев, при этом не выявлено отличий в эффективности в зависимости от источника ММСК (использование клеток донора костного мозга или другого донора). Терапия третьей и более линии резистентных форм острой РТПХ оказалась неэффективной при использовании любых иммуносупрессивных воздействий.

\section{Ключевые слова}

Трансплантация гемопоэтических клеток, рефрактерная РТПХ, кишечная форма, преднизолон, мультипотентные мезенхимальные стромальные клетки. 